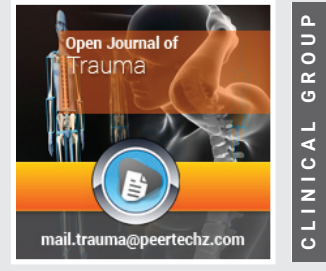

Case Report

\title{
Transepiphyseal separation of distal humerus: A case report and review of literature
}

Received: 14 February, 2020

Accepted: 06 June, 2020

Published: 08 June, 2020

*Corresponding author: Dinesh Dhar, Orthopedics Department, Nizwa Regional Referral Hospital, Nizwa, Oman, E-mail: dinesh612003@yahoo.com

https://www.peertechz.com

Check for updates

\author{
Dinesh Dhar* \\ Department of Orthopedics, Nizwa Regional Referral Hospital, Nizwa, Oman
}

\section{Introduction}

Transepiphyseal Fracture of Distal Humerus ( TFDH ) or epiphysiolysis of distal humerus is a rare injury seen in children younger than three years of age [1]. It is the least commonest of all physeal injuries representing 3.9\% of them in this age group [2]. The reported incidence of this injury is 1:35000 births [3]. The diagnosis of this condition is very challenging and in particular differentiating it from elbow dislocation is very difficult. Plain radiographs are not decisive since ossification centers around elbow are not ossified during this age group.

\section{Case report}

A one year old male child was brought to accident and emergency by his parents with Alleged history of fall a few hours back resulting in trauma to his left elbow presenting as pain , swelling and limitation of left elbow movements . Initial $\mathrm{X}$ rays of left elbow suggested TFDH .He was seen by on call orthopedic surgeon who treated it by closed reduction and above elbow plaster slab in 100 degrees flexion (Figures 1,2). On 12th day post trauma follow up antero posterior and lateral $\mathrm{x}$ rays of left elbow revealed loss of humero ulnar alignment with posteriorsuperior displacement of radio ulnar complex with early callus formation around distal humerus thus establishing the diagnosis of TFDH with early healing stage.

Under General anaesthesia closed manipulation with correction of deformity and application of posterior plaster slab was done. On $12^{\text {th }}$ day post trauma follow up anteroposterior and lateal $\mathrm{x}$ - rays of left elbow revealed loss of humero ulnar alignment with posterosuperior displacement of radio ulnar complex with early callus formation around distal humerus thus establishing the diagnosis of TFDH with early healing stage (Figure 3). The plaster slab maintained and at 4 weeks plaster splint was removed and child encouraged to start gentle elbow mobilization. On follow up at 14 weeks the TFDH had remodeled well and repeat radiographs showed healed fracture without displacement of bones with full range of movements of left elbow with no deformity without any shortening of affected limb (Figure 4).

\section{Discussion}

Transepiphyseal Fracture of Distal Humerus (TFDH) occurs in neonate and children below the age of three years because the physeal cartilage at the junction of the layer of cartilage hypertrophy and primary bone spongiosa is weaker than the bone. This rare injury was first reported by Camera in 1926 [4]. Very few case reports and case series have been published about this condition. This injury is a variant of supracondylar fracture seen in older children. Commonest causes of this

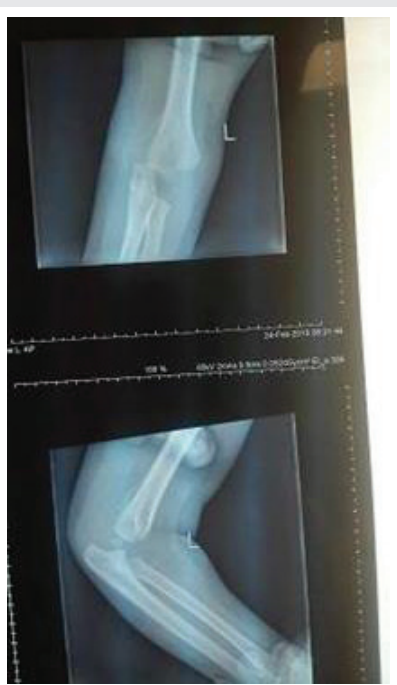

Figure 1: Radiograph post trauma.suggestive of TFDH. 


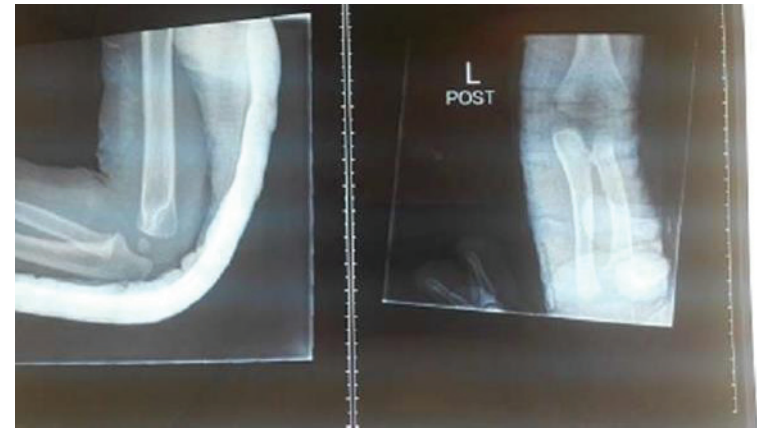

Figure 2: Radiograph after initial reduction

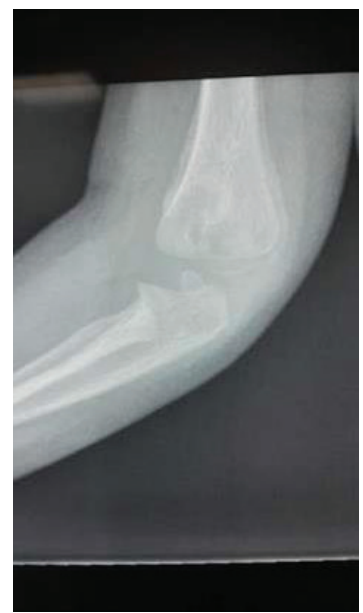

Figure 3: Radiograph at 12 days post injury after reduction.

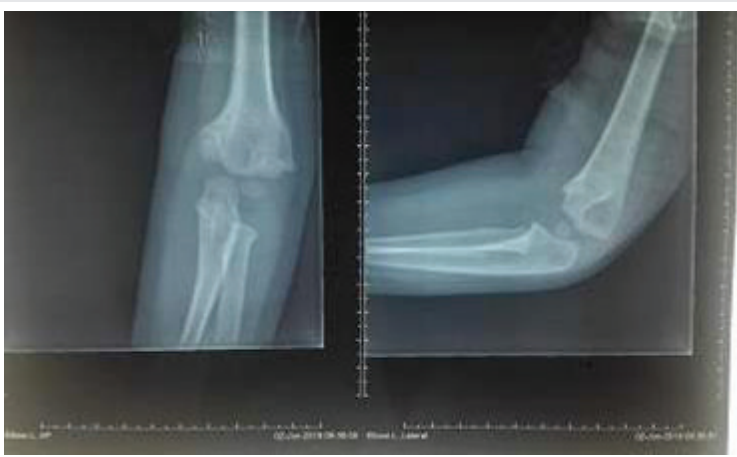

Figure 4: Radiograph at 14 weeks after injury showing healing with remodeling of TFDH.

injury include birth injuries (emergency caesarian sections and vaginal deliveries ) child abuse , falls and direct trauma $[3,5]$. Traumatic separation of epiphysis results from rotator shearing forces with fracture commonly extension type with distal epiphysis lying posterior to metaphysis [6].

\section{TFDH has been classified into three groups as per Delees classification}

Group A :TFDH (seen in infants upto12 months age) before the secondary ossification centre of the Capitellum appears without metaphyseal spike usually Salter Harris ( SH )Type 1 physis injury.

Group B :TFDH (seen in children 12 months to 03 years of age) with ossification centre of the Capitellum appears with metaphyseal spike indicating Salter Harris (SH )Type 2 physis injury.

Group C: TFDH (seen in older children between 03 and 07 years of age) with secondary ossification centre of the Capitellum with large metaphyseal fragment which may be confused with lateral condyle or low supracondylar fractures of humerus.

Clinically TFDH presents with swelling, tenderness and limitation of elbow joint movements associated with muffled crepitus. In Infants below 3 years of age with swollen elbow and pseudo paralysis secondary to trauma TFDH should be suspected.

Differential diagnosis includes traumatic dislocation of elbow , septic arthritis , osteomyelitis and possibility of child abuse or any metabolic disorder should be kept in mind.

The diagnosis of this condition is very challenging and in particular differentiating it from elbow dislocation is very difficult and plain radiographs are not decisive since ossification centres around elbow are not ossified during this age group .At best plain radiographs shows relationship of radioulnar complex and distal humerus metaphysis. In TFDH the radioulnar complex together with distal humeral epiphysis is displaced posteromedially (Figure 1). Elbow Ultrasonography, MRI scan and Arthrography are helpful in arriving at correct diagnosis.

Ultrasonography (USG) is a non invasive diagnostic procedure to differentiate elbow dislocation from distal humeral epiphysiolysis . The cartilaginous epiphysis appears as a hypoechogenic structure while the bones appear as highly echogenic structure. Moreover periosteal reaction can be seen as early as 7-10 days after injury confirming the diagnosis [3]. However the USG is operator dependent and painful in presence of fracture.

MRI (Magnetic resonance Imaging) is preferred mode of investigation as it visualizes soft tissues and bones in all planes without any manipulation of elbow and no exposure to ionizing radiation. Only limiting factor is that it is not available at all centres and is expensive. Ideally should be performed after the meal when the baby is fast asleep. Anesthesia is rarely required.

Arthrography is an invasive procedure with exposure to ionizing radiation and carries risk of infection and usually performed during definitive treatment to demonstrate the injury and is no longer practiced as MRI and Ultrasonography are safer mode of investigations.

TFDH even with delayed diagnosis conservative management has shown to have favorable outcome with any residual deformity correcting itself with growth even when anatomic relationship is not maintained initially possibly as in Salter Harris type 1 lesion the entire epiphyseal growth plate remains with epiphysis so damage to growth plate is not common $[3,5,6]$. Till date there is no consensus on optimal treatment for TFDH, if the displacement is mild, only casting 
is performed. In other cases, to achieve anatomically aligned closed reduction, percutaneous pinning or open reduction and fixation are performed [7-11]. Early diagnosis is important to allow reduction of the fracture by closed manipulation. Many authors recommend avoiding late manipulation after 4-7 days) owing to concerns about avascular necrosis, trauma to the growth plate, and disturbance of growth [11]. Some authors prefer intraoperative arthrography for these patients because of the difficulty in visualizing the distal humeral anatomy in very young children $[1,4]$, for obtaining good alignment of fracture and stability in such cases [12].

Limitation of range of movements , cubitus varus and rarely cubitus valgus as have been reported as long term complication associated with TFDH [1-3]. which can be treated in later childhood by osteotomies if required.

\section{Conclusion}

TFDH is a rare injury which can be easily missed as it is confused with posterior dislocation of elbow and only high index of suspicion can help in correct diagnosis Diagnosis of this condition can be estabilished by ultrasonography, MRI, Arthrography. Favourable functional outcome can be obtained with closed reduction and plaster cast splint or percutaneous pinning . Cubitus varus is the most common complication described

\section{References}

1. Zhow W, Canavese F, Zhang L, Li L (2019) Functional outcome of elbow in toddlers with transepiphyseal fracture of the distal humerus treated surgically. J Child Orthop 13: 47-56. Link: https://bit.ly/3eTumyV
2. Malik S, Khopkhar SR, Kopday CS, Jadhav SS, Bhaskar AR (2015) Transepiphyseal Injury of distal Humerus : A Commonly Missed Diagnosis in Neonate. J Clin Diagn Res 9: SD01-SD02. Link: https://bit.ly/374512R

3. Ratti C, Guindani N, Riva G, Callegari L, Grassi FA, et al. (2015) Transphyseal elbow fracture in newborn: review of literature. Musculoskelet Surg 97: 99105. Link: https://bit.ly/3cEMds7

4. Camera U (1926) Total, pure, traumatic detachment of inferior humeral epiphysis. Chir Org Movemento 294-316.

5. Solgun HA, Yurdarsik I (2019) Distal Humeral Epiphyseal Separation on a Premature Newborn. Sch J Appl Sci Res 2: 12-14. Link: https://bit.ly/2XGPBi1

6. Steropoulos NK (2017) Traumatic Separation of the distal Humeral Epiphysis ARC Journal of Orthopedics 2: 24-28. Link: https://bit.ly/2Y3M6RD

7. Shrader MW (2008) Pediatric supracondylar fractures and pediatric physeal elbow fractures. Orthop Clin North Am 39: 163-171. Link: https://bit.ly/3cF3Yr2

8. Abe M, Ishizu T, Nogaoka T, Onomura T (1995) Epiphyseal separation of the distal end of the humeral epiphysis: a follow-up note. J Pediatr Orthop 15: 426 434. Link: https://bit.ly/2Mwaq9p

9. Mizuno K, Hirohata K, Kashiwagi D (1979) Fractureseparation of the dista humeral epiphysis in young children. J Bone Joint Surg Am 61: 570-573. Link: https://bit.ly/3cALeJd

10. DeLee JC, Wilkins KE, Rogers LF, Rockwood CA (1980) Fracture-separation of the distal humeral epiphysis. J Bone Joint Surg Am 67: 46-51. Link: https://bit.ly/3gYQQ3G

11. Supakul N, Hicks RA, Caltoum CB, Karmazyn B (2015) Distal Humeral Epiphyseal Separation in Young Children: An Often-Missed FractureRadiographic Signs and Ultrasound Confirmatory Diagnosis. AJR Am J Roentgenol 204: W192-W198. Link: https://bit.ly/372INhE

12. Tharakan SJ, Lee RJ, White AM, Lawrence JT (2016) Distal Humeral Epiphysea Separation in a Newborn. Orthopedics 39: 764-767. Link: https://bit.ly/3eTtoT

Copyright: @ 2020 Dhar D. This is an open-access article distributed under the terms of the Creative Commons Attribution License, which permits unrestricted use

distribution, and reproduction in any medium, provided the original author and source are credited.

Discover a bigger Impact and Visibility of your article publication with Peertechz Publications

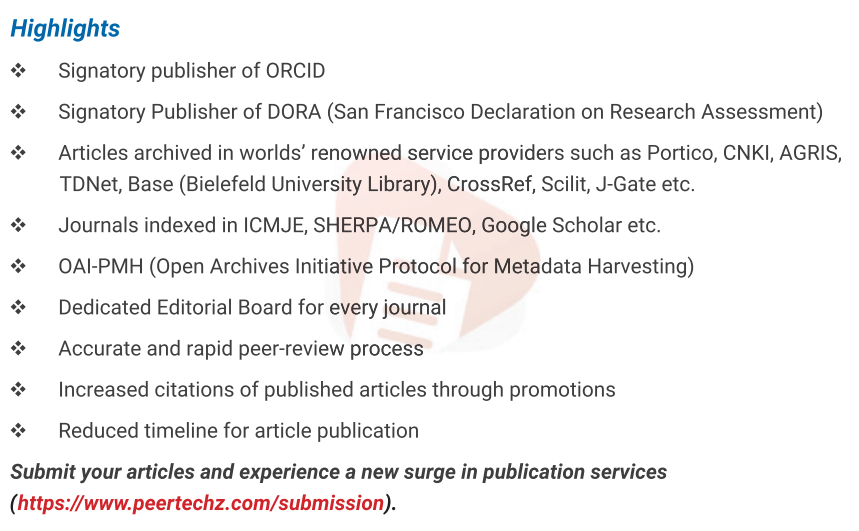

Peertechz journals wishes everlasting success in your every endeavours. 